\title{
Material Selection and Process Configuration for Free-Form, Voluminous and Textile-Based Multi-Material-Design by the Example of a Bucket Seat
}

\author{
Jonas Stiller ${ }^{1, a}$, Kay Schäfer ${ }^{1, b}$, Frank Helbig ${ }^{2, c}$, Jürgen Tröltzsch ${ }^{1, d}$, \\ Daisy Nestler ${ }^{1, \mathrm{e}}$, Lothar Kroll ${ }^{1, \mathrm{f}}$ \\ ${ }^{1}$ Institute of Lightweight Structures, Chemnitz University of Technology, \\ 09107 Chemnitz, Germany \\ ${ }^{2}$ Spiga GmbH, Gewerbegebiet 2, 09557 Flöha, Germany

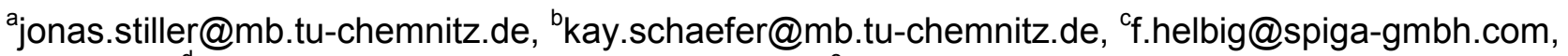 \\ djuergen.troeltzsch@mb.tu-chemnitz.de, ${ }^{e}$ daisy.nestler@mb.tu-chemnitz.de, \\ flothar.kroll@mb.tu-chemnitz.de
}

Keywords: textile-based multi-material-design, sandwich construction, organic sheet, polyurethane foam, spacer fabric

\begin{abstract}
Hybrid textile-based composites possess an enormous potential for energy and resource efficient large-scale production, with freedom in and high specific mechanical properties. This paper covers the connection of available and established production processes for textiles in a differential process chain for the manufacturing of complex shaped and elastic sandwich components. The technology enables both stiffness and comfort through elasticity.

OLU-Preg ${ }^{\circledR}$-organic sheets, polyurethane foam cores and 3D-spacer fabrics form the targeted properties of demonstrator models. This article refers to the demonstrator part "bucket seat". To show the benefit of complex composite material, the lightweight and mechanical properties of the sandwich structures are tested in several variations of core and comfort shapes. Absolute and specific improvements of performance are shown in static and dynamic examinations. An Analysis of coupling effects, deformation and failure behavior of the multi-material design (MMD) complete the scientific approach of the structure-property relationships of hybrid composites.
\end{abstract}

\section{Introduction}

Hybrid textile-based processes are the key to an efficient and sustainable large-scale production of lightweight composites [1,2,3]. The textile approach of the used MMD allows free-form shapes of all components and both adaptable stiffness and damping. The usage of established textile technologies, free-in-design materials and large-scale production processes enable efficient process chains for customized MMD products. The comparison of common and hybrid components shows the benefit of the combination of different materials. In the course of this, elastic bendable and nonbendable materials are combined for customizable stiffness and damping properties

The design of complex textile materials and technologies plus the transfer into products is the subject of the research. The target is the development of lightweight structures produced in highly efficient textile-based processes for large-scale productions.

\section{State-of-the-art}

Organic sheets - surface shells. Organic sheets are flat semi-finished products, consisting of reinforcement fibers embedded in a thermoplastic matrix. In comparison to thermoset fiberreinforced plastics (FRP), thermoplastic organic sheets have a high potential for large-scale production of complex shell shapes, due to their thermoforming ability within short cycle times.

The high viscosity of compact polymer melts complicates the full impregnation of reinforcement structures, which has fundamental impact on the mechanical properties of the resulting FRP. Organic sheets with alternating stapled non-crimp glass fabrics and thermoplastic polypropylene 
non-woven face this challenge with short flow paths. Moreover, the textile-based matrix preserves the reinforcement during the OLU-Preg ${ }^{\circledR}$ manufacturing process with its temperature and pressure emission [4]. OLU-Preg ${ }^{\circledR}$ is a thermoplastic non-crimp fabric (TP-NCF) organic sheet concept consisting of layers of thermoplastic fleece (spun bonded PP) and layers of unidirectional glass fibers in an interchangeable manner [5]. The material is produced in three steps: fiber and matrix layers are stitched together by a binder yarn of the same material as the fleece. The textiles are then cut to the required size and hot pressed resulting in fleece and binder yarn to melt completely and to create a consolidated NCF organic sheet. The structuring of the precursor textiles enable the preservation of its textile structure during production creating unidirectional and independent reinforcement layers without undulation. The usage of already established textile technology facilitates an affordable large-scale production of textile precursors.

Textile technologies offer several variabilities in material and process compatibility for loadadapted engineering in soft elastic sandwich components. With their mechanical properties, OLUPreg $^{\circledR}$ organic sheets from SKL Schwergewebekonfektion Lichtenstein GmbH fulfill the requirements for surface shells of sandwich parts with complex shapes.

Fig. 1 shows the principal ply book of the used organic sheet with eight glass reinforcement layers with an orientation as shown, a fibre volume content of $43 \%$, a grammage of $1.4 \mathrm{~kg} / \mathrm{m}^{2}$ and a thickness of $1.65 \mathrm{~mm}$.

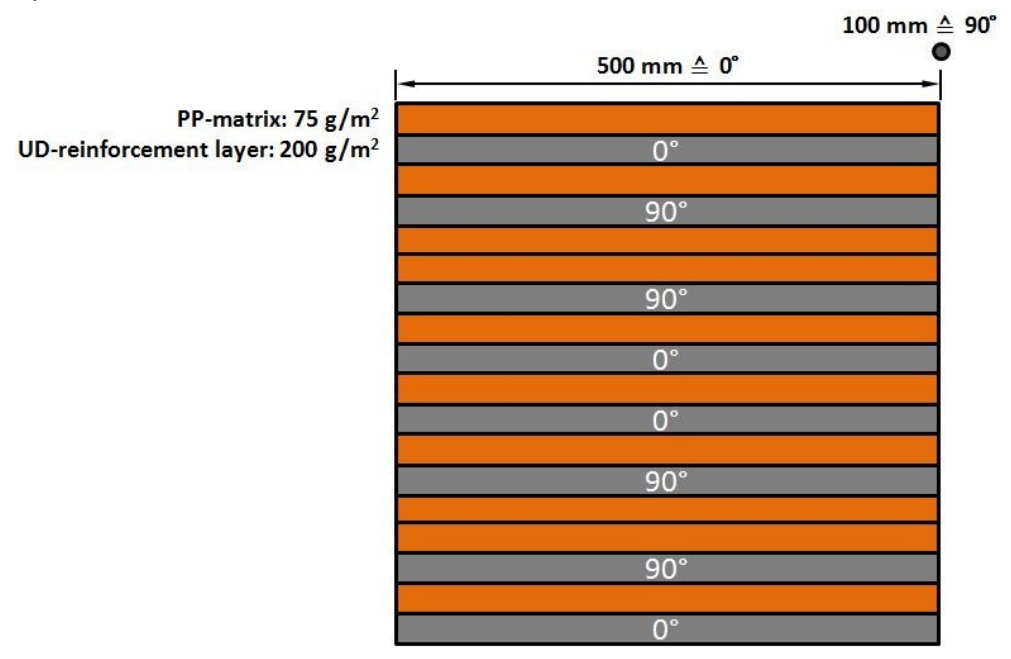

Fig. 1: Ply book of organic sheet structure

The omission of the final matrix layer on top leads to an improved connectivity between the organic sheet and the foam cores. Through open glass fiber structures, which are partially embedded in the matrix and can take loads through micro porous form fit, the surface shells can be connected to the sandwich core material.

Foam - sandwich core. The sandwich design is based on lightweight core material and the distance between the stiff and thin surface material, which porous and cellular plastics offer. Polyurethane (PUR)-foam has both low viscosity and low cubic density and is used as core material for component stiffening and for damping between the organic sheets. PUR-foam is a reaction product of polyol and isocyanate [6]. During the chemical reaction carbon dioxide emerges, expands the low viscous PUR, and is subsequent capable of penetrating and infiltrating fine textile structures. The inner pressure of the emitted $\mathrm{CO}_{2}$ prevents sink marks and shrinkage. The standard usage of PUR as adhesive provides a high compatibility in multi-material components. The PUR soft elastic foam is based on commercial products from Covestro AG.

Spacer fabrics - reinforcing and comfort component. Spacer fabrics are high distance warp knitted textile structures, produced on right/right Raschel machines (type "High distance ${ }^{\circledR}$ ") with a thickness of up to $65 \mathrm{~mm}$ [7,8], with two surface layers and knitted with mono filament spacer threads. They are divided by their design into closed and compacts Fig. 2a and open and net shaped spacer fabrics Fig. 2b. 


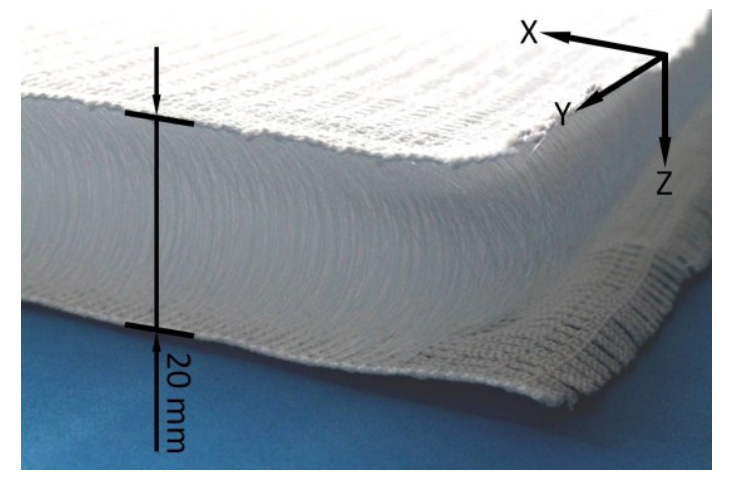

a)

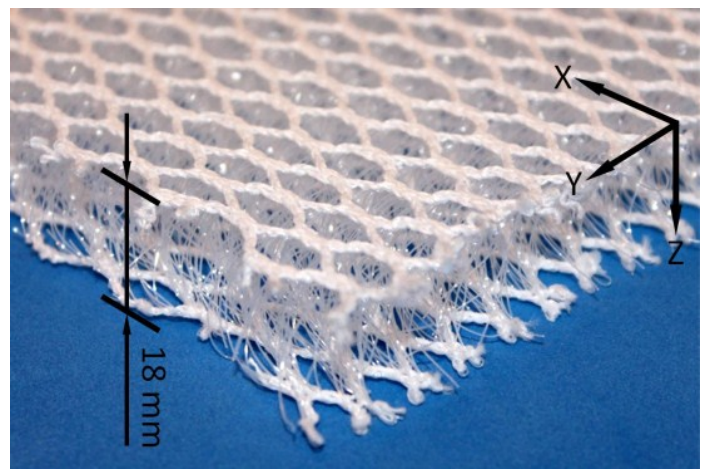

b)

Fig. 2: a) AG1 closed and compact spacer fabrics. b) AG2 open and net shaped surface spacer fabric

Based on research during pervious projects, spacer fabrics are used for the reinforcement of flexible and rigid foam cores [9,10]. Without further process steps, the spacer fabrics are easily infiltrated by the PUR-foam increasing the stiffness of the emerging foam-spacer fabric composite. Between two organic sheets, this composite has the function of a sandwich core material.

The second application of the spacer fabrics is cushioning. Due to their flexibility and breathability, thermoplastic spacer fabrics fulfill the requirements for cushions. The typical application for lightweight spacer fabrics is cushioning seat structures with active air conditioning [11]. Through parametric processes, space density, stiffness and thickness can be customized for different applications. Common material for spacer fabrics is polyethylene terephthalate (PET), which is also the base for these examinations.

Spacer fabrics for the reinforcement of sandwich cores are primarily selected after their thickness, as it specifies the thickness of the core. In this examination, the compact AG1 was used as cushion and the open AG2 as reinforcement structure in the core. Their properties are given in Table 1.

Table 1: Properties of reinforcement (AG1) and comfort (AG2) spacer fabrics

\begin{tabular}{|l|l|l|l|l|l|l|}
\hline $\begin{array}{l}\text { 3D spacer } \\
\text { fabric }\end{array}$ & $\begin{array}{l}\text { Thickness } \\
{[\mathbf{m m}]}\end{array}$ & $\begin{array}{l}\text { Space } \\
\text { density } \\
{\left[\mathbf{k g} / \mathbf{m}^{3}\right]}\end{array}$ & $\begin{array}{l}\text { Fibre } \\
\text { volume } \\
\text { content } \\
{[\%]}\end{array}$ & $\begin{array}{l}\text { No. of } \\
\text { spacer } \\
\text { threads } \\
{\left[\mathbf{1} / \mathbf{i n}^{2}\right]}\end{array}$ & $\begin{array}{l}\text { Diameter } \\
\text { of mono } \\
\text { filaments } \\
{[\mathbf{m m}]}\end{array}$ & $\begin{array}{l}\text { Surface } \\
\text { porosity } \\
{[\%]}\end{array}$ \\
\hline AG1 & 18 & 36 & 2,6 & 140 & 0,25 & 65 \\
\hline AG2 & 20 & 68 & 4,9 & 420 & 0,20 & 10 \\
\hline
\end{tabular}

\section{Experiments}

Manufacturing. The manufacturing of the spring demonstrator takes place in three steps. First step is the thermoforming of the organic sheets. Before thermoforming, the cuts of the parts are cut out by a water jet. The organic sheets are heated for $120 \mathrm{sec}$ in a contact-heating device then placed in a mould at ambient temperature and formed. Shortly after forming, the temperature decreases to handling temperature. The whole forming process lasts roughly $3 \mathrm{~min}$.

In the second step, the bottom and top surface are placed into the PUR-reaction mould. The draped spacer fabrics set the distance between the two surface shells. On top of the upper shell another spacer fabric is placed as cushion and the mould is closed. In the last step, after the infiltration with the chemical precursors that is part of the core material of the MMD-sandwich, the PUR-foam reaction proceeds. During the foam reaction, the foam flows through little notches in the upper shell and slightly penetrates the knitted base areas of the spacer fabrics.

In a $2 \mathrm{~K}$-mix and dispense low pressure system of Unipre $\mathrm{GmbH}$ the foam precursors are mixed and dispensed. Low pressure systems are recommended for the manufacturing of textiles and textile-based materials due to the low mechanical influences of the reactive material and, furthermore, the omission of fixation systems inside the mould. The material is ejected through a 
mixer jet into the aluminum mould with the dimension of $500 \mathrm{~mm} \times 100 \times 5-20 \mathrm{~mm}(\mathrm{~L} \times \mathrm{W} \times \mathrm{H})$, subsequently, the foam expands and hardens. The low viscosity of the reactive basic PUR-chemicals allow a full impregnation of the spacer threads of the 3D-fabrics. During the expansive reaction of the foam $\mathrm{CO}_{2}$ is emitted as propellant, raising sufficient pressure to completely fill the mould. The surface shells, the reinforcing spacer fabrics and the cushioning spacer fabrics are integrally implemented through adhesion and micro fitting. The expanding chemical foam reaction was simulated and validated parallel to these experiments [12].

The usage of textile-based organic shells, lightweight spacer fabrics and a high fluidity allows a free design while achieving high mechanical properties in the components.

Earlier examinations of adhesion between different surfaces showed incompatibility between PUR foam and PP, the matrix material of the organic sheets. The single sided micro porous surface of the OLU-Preg ${ }^{\circledR}$ organic sheet has a critical influence on the manufacturing of MMD components. A connection between PUR-foam and organic sheets is only possible with specific adhesion and micro fitting of the glass fibers.

Structure of demonstrator. The MMD demonstrator is a sandwich-based component with two organic sheet surfaces and a spacer fabric reinforced PUR core. On top is a lightweight spacer fabric cushion that is bonded to the top layer organic sheet trough adhesion and micro fitting. The demonstrator is shown in Fig. 3 in exploded drawing. The two organic sheets are attached via groove-lug connection, visible in the top left picture. The reinforcement spacer fabrics and the bonding PUR-foam are the core material between them. Through the lengthwise notches the foam can connect to the cushion and glue it to the structure.
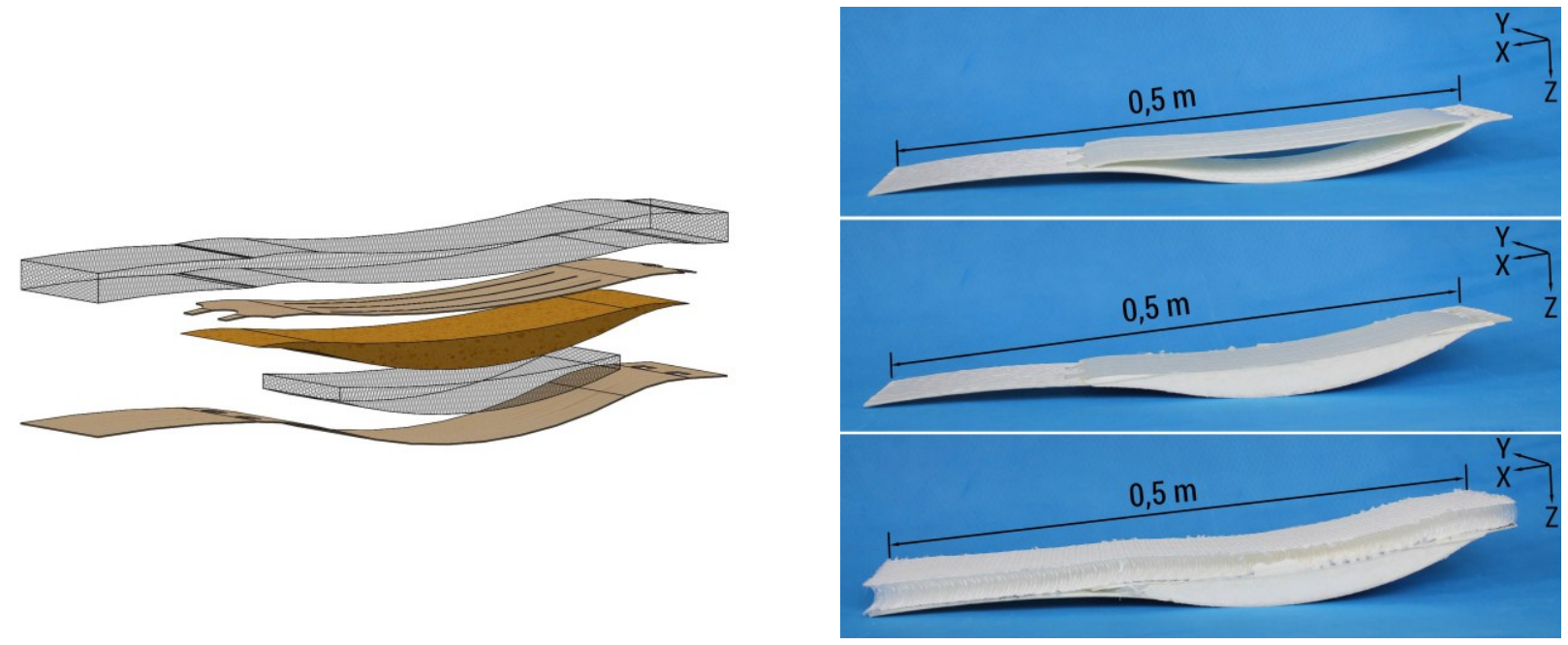

Fig. 3: MMD-demonstrator in CAD; MMD-demonstrator in different variants

To examine the influence of the cushion and the stiffness of the sandwich core alternate variants were manufactured: Without cushion, without cushion and reinforcement, and finally, with cushion and without reinforcement. All variants passed two three-point bending tests: Static and dynamic.

\section{Results and discussion}

In variation of core design and presence of cushion, the lightweight properties of the MMD demonstrator were tested according to DIN EN ISO 178 statically and the Wöhler fatigue test and subsequently compared to each other. The five variations of test specimen with their mass and volume fractures of their elements are detailed in Table 2.

Although organic sheets have the least volume, they have the highest mass share, while inside a sandwich construction those surface shells mostly take the tensile and compression forces during bending loads. The mass saving of the core is perfectly realized in the not cushioned MMD through usage of the spacer fabric reinforced foam core with a mass share of $22 \%$ while having a volume share of $87 \%$. A load adaptable concept for MMD-sandwich components is received. 
Table 2: Mass and volume distribution of different variations

\begin{tabular}{|c|c|c|c|c|c|}
\hline & $\begin{array}{l}\text { Not } \\
\text { cushioned } \\
\text { without foam } \\
\text { core }\end{array}$ & $\begin{array}{l}\text { Not } \\
\text { cushioned } \\
\text { with } \\
\text { unreinforced } \\
\text { foam core } \\
\end{array}$ & $\begin{array}{l}\text { Not } \\
\text { cushioned } \\
\text { with } \\
\text { reinforced } \\
\text { foam core } \\
\end{array}$ & $\begin{array}{l}\text { Cushioned } \\
\text { with } \\
\text { unreinforced } \\
\text { foam core }\end{array}$ & $\begin{array}{l}\text { Cushioned } \\
\text { with } \\
\text { reinforced } \\
\text { foam core }\end{array}$ \\
\hline Height [mm] & 25 & 25 & 25 & 45 & 45 \\
\hline Density $\left[\mathrm{kg} / \mathrm{m}^{3}\right]$ & 420 & 400 & 450 & 190 & 200 \\
\hline Mass [g] & 190 & 220 & 245 & 280 & 310 \\
\hline \begin{tabular}{l|} 
Mass distribution \\
Organo sheet \\
PUR-foam \\
\\
Spacer fabric for reinforcement \\
Spacer fabric for cushion \\
\end{tabular} & & & & & \\
\hline $\begin{array}{l}\text { Volume distribution } \\
\text { Organo sheet } \\
\text { PUR-foam } \\
\text { Spacer fabric for reinforcement } \\
\text { Spacer fabric for cushion }\end{array}$ & & & & & \\
\hline
\end{tabular}

At first, the specimen were statically tested with a constant movement of $1 \%$ bending strain up to $100 \mathrm{~mm}$ deformation for specimen with cushion and $80 \mathrm{~mm}$ for specimen without cushion. The main failure is partial failure of the top surface organic sheet in the area of load introduction. The interface between shell and core was not damaged during material testing.During the test of the pure organic sheets structure the top shell bends until contact with the bottom shell resulting in both shells to bend as shown in Fig. 4a, whereas an unreinforced foam core prevents the contact of organic sheets over a longer period of time, but the demonstrator deforms high locally. The reinforced core prevents contact of organic sheets completely. Instead, they move parallel, as shown in Fig. 4b. In addition, an increase of strength and stiffness of about $50 \%$ of the reinforced core was measured, with decreased distance to first local failure though. The specimen with cushion (s. Fig. 4c) increases the total demonstrator height by $20 \mathrm{~mm}$, resulting in shifted curves in the diagram in Fig. $4 \mathrm{~d}$. As expected the stiffness of the component is considerably decreased by the cushioning but the loading pin does not deform the cushion at first, the whole structure bends jointly as shown in fig. 4c. Therefore, the deformation of all components from the start of loading prove the excellent interphase MMD connections.

a) Organic sheet structure

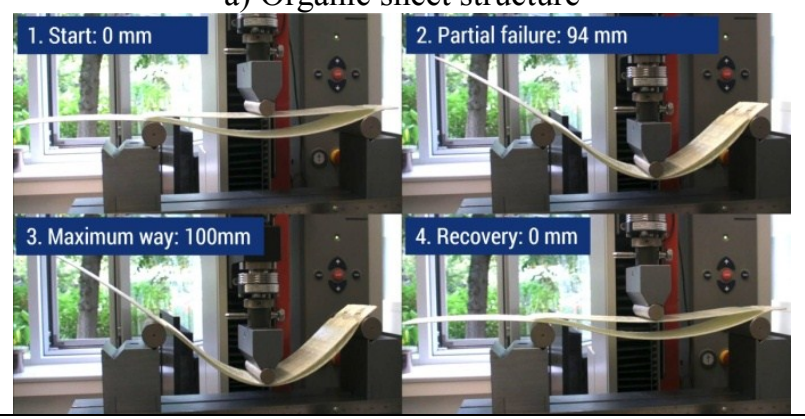

c) Cushioned with unreinforced foam core

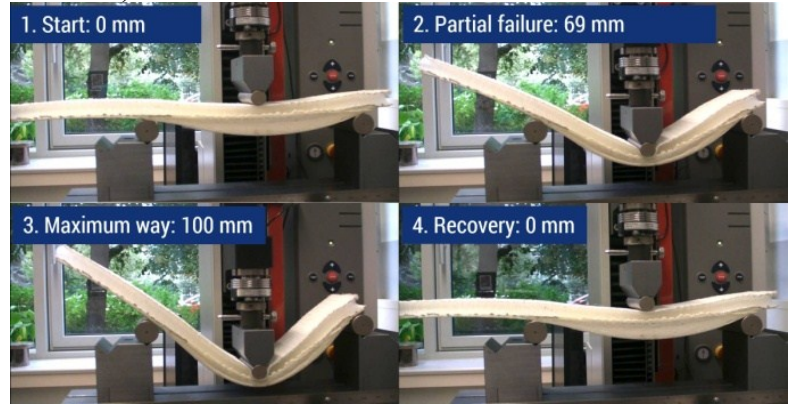

b) Not cushioned with reinforced foam core

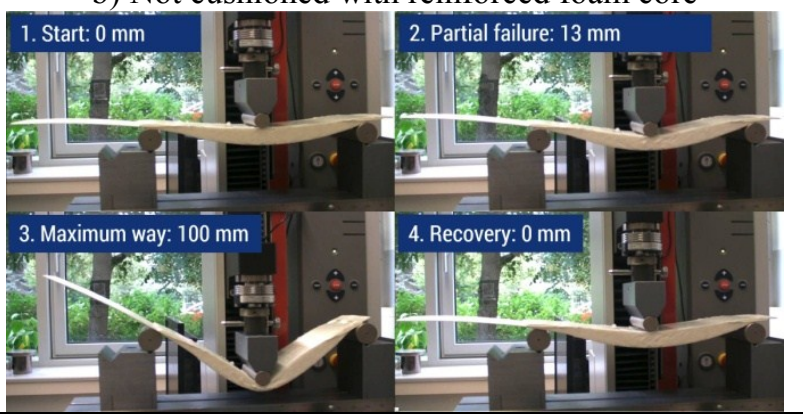

d) Force-distance measurement curves

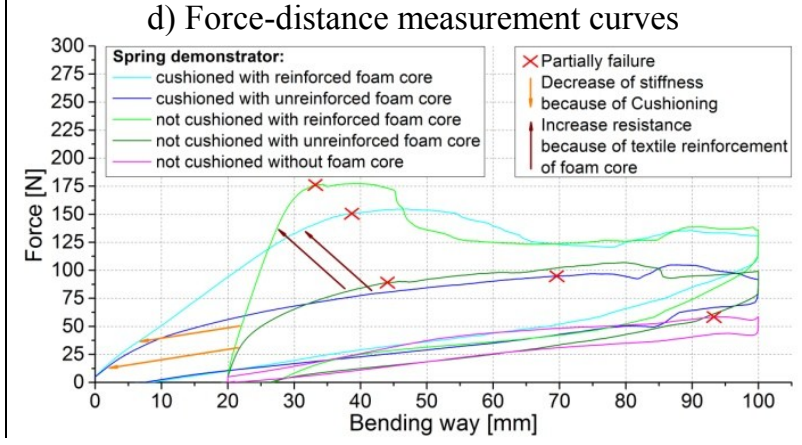

Fig. 4: Deformation behavior of spring demonstrators and force-distance diagram of bending tests according to DIN EN ISO 178 
In the second stage, new specimen were dynamically tested in 100.000 cycles with a maximum of $80 \%$ failure deformation of the lowest specimen in the static test. The load is introduced as a constantly path-controlled sine oscillation and the resulting force is measured in order to demonstrate the quality of those interphase connections. One cycle lasts $1.06 \mathrm{~s}$ or $3 \mathrm{~s}$ resp. for cushioned specimen. The upper vertex $(\pi / 2)$ is the starting point. At this point, the loading pin does not contact the specimen and the force is zero. Subsequently, the loading pin moves down for $10.5 \mathrm{~mm}$ resp. $30.5 \mathrm{~mm}$ for cushioned specimen and is afterwards released. With progressing cycles the specimen does not move upwards until an initial position, a so-called setting, is visible and a force of zero is measured. In Fig. 5a, the loading and unloading curves for the cushioned specimen with unreinforced foam core are given with four single curves of specific cycles. The setting is already visible after 500 cycles and increases progressively.

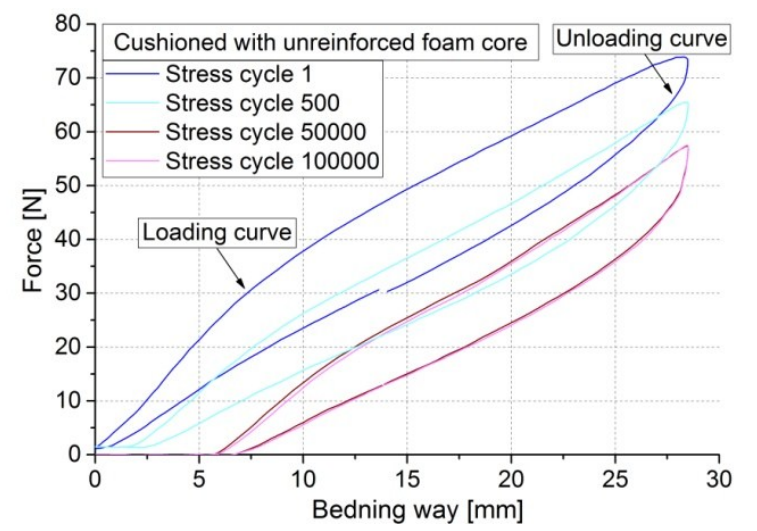

a)

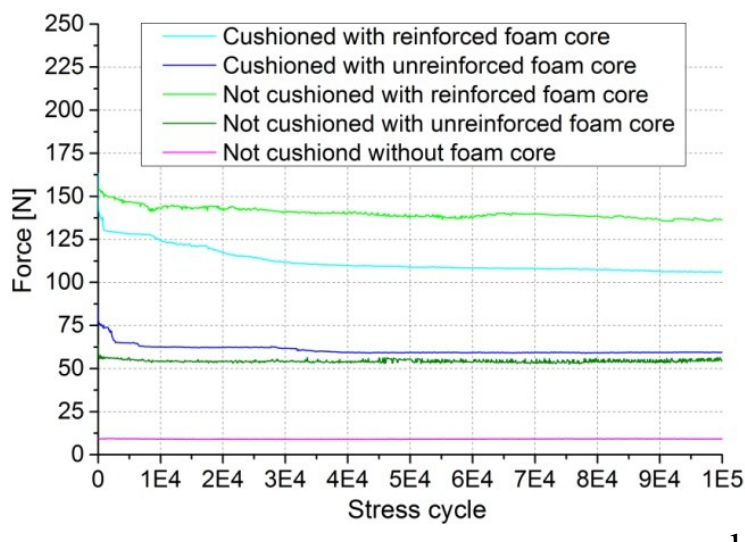

b)

Fig. 5: Curves of measured maximum force over 100.000 cycles

Fig. $5 \mathrm{~b}$ shows the development of the maximum force over the total of 100.000 cycles. Although the maximum force decreases progressively the fatigue strength of $135 \mathrm{~N}$ can be assumed for the best variant.

The Wöhler fatigue test did not cause any lasting deformation and no damage of the lightweight structures. In addition, the MMD interface was damage free. The bucket seat structure will be considered for a practical applicability of the demonstrator. The demonstrator is just a $100 \mathrm{~mm}$ wide section of a seat with a bending length of $300 \mathrm{~mm}$ and is loaded with a linear load. The load affects an area of $100 \times 300 \mathrm{~mm}^{2}$. The loaded area of a seat is approx. three times higher, which is why the fatigue strength of $450 \mathrm{~N}$ can be extrapolated for the seat.

\section{Outlook}

In this study, the complex manufacturing process of different materials was examined. The spring demonstrator provides the concept for larger lightweight MMD-structures [13]. Further development and structural improvements are planned such as the development of the twin-shell bucket seat shown in Fig. 6. 


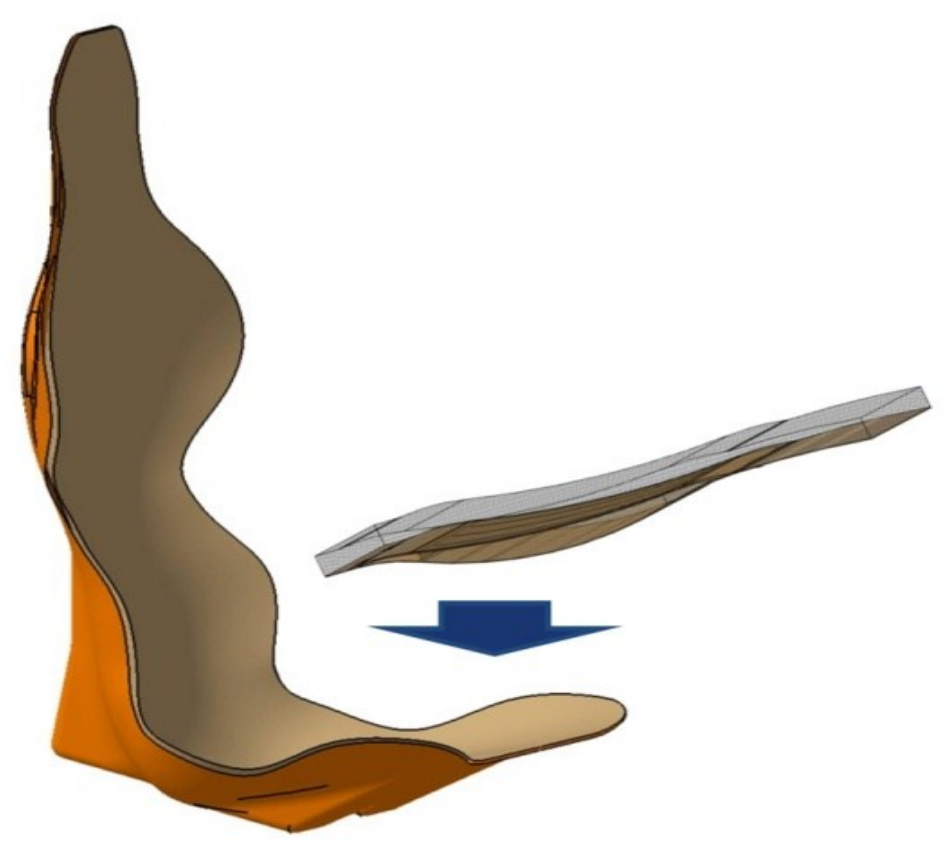

Fig. 6: Spring demonstrator as specimen for designing the twin-shell bucket seat

Also different test methods like CT scan under load [14] or further micro mechanical examinations to prove the MMD concept will be performed. Further tests and optimization of adhesion in MMD structures will be used for designing the bucket seat. Thereby, the multifunctional characterization of the functional demonstrators are the requirement for the merging of different manufacturing processes into one efficient integral production process. For the transfer of the spring demonstrator to the seat, the technological requirements must be compared and adjusted.

\section{Acknowledgements}

This work was performed within the Federal Cluster of Excellence EXC 1075 "MERGE Technologies for Multifunctional Lightweight Structures", supported by the German Research Foundation (DFG) and within the project Pafatherm II (03IPT508X) in the initiative "InnoProfile Transfer" of the Federal Ministry of Education and Research (BMBF). Financial support is gratefully acknowledged.

\section{References}

[1] J.M. Patel, B.A. Modi, Stiffness and Thermal Analysis of Doubly Curve Sandwich Panel for an Automobile Application, Procedia Engineering, 51 (2013) pp. 655-664.

[2] A. Esnaola, I. Ulacia, B. Elguezabal, E. del Pozo de Dios, J.J. Alba, I. Gallego, Design, Manufacturing and Evaluation of Glass/Polyester Composite Crash Strctures for Lightweight Vehicles. International Journal of Automotive Technology 17 (2016) pp. 1013-1022.

[3] J.-M. Lee, K.-H. Lee, B.-M. Kim, D.-C. Ko, Design of Roof Panel with Required Bending Stiffness using CFRP Laminates. International Journal of Precision Engineering, 17 (2016) pp. 479-485.

[4] N. Brunk, E. Gründig, F. Helbig, M. Reinhardt, M. Scheika, C. Unger (SKL Schwergewebekonfektion Lichtenstein GmbH) DE102012007631, 2012.

[5] F. Helbig, M. Scheika, Dünnschichtlaminate aus textilverstärktem FKV. Konstruktionswerkstoffe, MM MaschinenMarkt 50/51 (2014) 28.

[6] G. Oertel, L. Abele, Polyurethane: Mit 126 Tab, 3rd ed., Hanser, München [u.a.], 1993. 
[7] J. Födisch, F. Helbig, Contour knitting machine with extended functions, Technische Textilien 42 (1999) 53-56.

[8] F. Helbig, New dimensions for functional, regular 3D knitting, Melliand Textilberichte 87 (2006) 153-155.

[9] K. Schäfer, B. Meier, S. Anders, F. Helbig, L. Kroll, A strengthening bond: Composites made from 3D warp-knitted textiles and polyurethane foam have a considerable reinforcing effect, Kettenwirk-Praxis 2 (2014) 34-36.

[10] K. Schäfer, S. Valentin, B. Meier, I. Roth, F. Helbig, Comparing composites made from hard and soft materials: Increasing the performance of rigid, hard pur foams by incorporating soft, elastic 3D warp-knitted textiles, Kettenwirk-Praxis 4 (2014) 32-35.

[11] F. Helbig, Study of the characteristics of space textiles: Study of shaped, 3D warp-knitted textiles made from geometrical elements and the influence exerted by the manufacturing process on their charateristics, Kettenwirk-Praxis 3 (2007) 17-19.

[12] I.E. Ireka, D. Niedziela, K. Schäfer, J. Tröltzsch, K. Steiner, F. Helbig, T. Chinyoka, L. Kroll, Computational modelling of the complex dynamics of chemically blown polyurethane foam, Phys. Fluids 27 (2015) 113102.

[13] F. Helbig, N. Mach, M. Scheika, K. Schäfer, J. Tröltzsch, L. Kroll (SKL Schwergewebekonfektion Lichtenstein GmbH, Pressless GmbH) WO2016177357 A1, 2016.

[14] R. Böhm, J. Stiller, T. Behnisch, M. Zscheyge, R. Protz, S. Radloff, M. Gude, W. Hufenbach, A quantitative comparison of the capabilities of in situ computed tomography and conventional computed tomography for damage analysis of composites, Composites Science and Technology 110 (2015) 62-68. 